\title{
LA REDENCIÓN DE LA MADRE EN LA FAMILIA DE PASCUAL DUARTE
}

\author{
Claire M. Ziamandanis
}

La fecundidad de la novela La familia de Pascual Duarte, de Camilo José Cela, se atestigua en una larga historia de crítica literaria, y en la gran variedad de interpretaciones que se han hecho de la obra'. Las diversas interpretaciones se han fijado en los niveles sociales, morales y psicológicos, además de los temas del machismo, la técnica narrativa y la realidad histórica de España de la posguerra. Aun siendo así, la riqueza de la obra también se comprueba en su perduración: ya medio siglo después de publicarse, y al cabo de mucha atención crítica, aún quedan elementos de la novela que pueden comentarse; el lector tiene en la mano un tesoro todavía lleno de posibilidades.

El presente estudio pretende agregar un nuevo enfoque: la redención de la madre. Se estudiará el vocabulario empleado en la descrpción de la madre, y la técnica narrativa, la autobiográfica (que ayuda a confirmar el creciente odio que expresa Pascual hacia su madre). Además, como narrador de su propia historia, Pascual decide no dar nombre a su madre, único personaje que no lo recibe. Finalmente, los últimos símbolos que emplea Pascual para describir a su madre sirven para descubrir el verdadero sentido de culpabilidad que Pascual ha rehuído a través de toda la novela.

La madre aparece en el segundo capítulo², descrita con un vocabulario poco halagador: es larga, chupada, con tez cetrina y mejillas hondas ${ }^{3}$. Nos dice que

1 Los estudios más reconocidos sobre la novela incluyen: Paul Ilie, La novelística de Camilo José Cela Madrid, Gredos, 1963; Robert Spires, «Systematic Doubt: The Moral Art of La familia de Pascual Duarte» Hispanic Review, 40, 1972, 283-302; Robert Spires, «Técnica y tema en La familia de Pascual Duarte: tres incidentes claves» Ínsula, 298, Sept. 1971, 1, 13; Mary Ann Beck, «Nuevo encuentro con La fanilia de Pascual Duarte» Revista Hispánica Moderna, 30, 1964, 279 298. Otros críticos que han avanzado interpretaciones importantes al estudio de la obra incluyen: Gregorio Marañón, J.S. Bernstein, Alonso Zamora Vicente, David M. Feldman, John W. Kronik, Robert Kirsner y Gonzalo Sobejano.

2 El presente estudio maneja la edición de Destinolibro, Barcelona, septiembre 1994.

3 Ídem, pág. 30 . 
parece tísica, que no se baña, y que es violenta y amiga del vino ${ }^{4}$. Para su padre, Pascual logra encontrar cualidades si no positivas, por lo menos que mitigan su estado desgraciado: demuestra ternura paternal, y devoción extrema hacia Rosario ${ }^{5}$, sentimientos que permiten que el lector sienta cierta simpatía hacia él. Para la madre, Pascual no tiene ninguna cualidad positiva, y por tanto, ni intenta atenuar sus cualidades negativas.

Para confirmar esta valoración fuertemente crítica, Pascual se apodera de las descripciones que otros hacen de esa mujer. Su padre le llama ignorante, bruja, bribona y zorra ${ }^{6}$. La señora Engracia, ante el parto de Rosario, la llama descreída y mala cristiana ${ }^{7}$.

Aunque Pascual insiste en su poca habilidad literaria, emplea una gran variedad de metáforas y símiles para mejor expresarse, y entre éstos, la descripción de la madre se intensifica y vivifica. Pascual emplea los siguientes símbolos para describirla: basilisco, media machorra, vendaval, perra parida con los cachorros, fuente que no mana, bruja ${ }^{8}$. La supuesta fecundidad materna en la expresión perra parida con los cachorros encubre una crítica fortísima de Pascual: emplea esta expresión cuando la madre ha rechazado a Mario delante del señor Rafael, para luego recogerlo al marcharse éste, causando así un aumento del odio que Pascual siente hacia su madre. La expresión no se fija en la fertilidad materna, sino en las cualidades animales de la madre.

Después de la muerte del hijo Pascualillo, la madre se involucra, participando en el círculo de mujeres que se empeñan en amargarle la vida a Pascual. Describe a las tres mujeres como grajos, ingratas, malignas, un castigo del cielo, cuervos, serias como carabineros, agobiadoras como las andaduras de los asnos ${ }^{10}$.

Una y otra vez, Pascual juzga a su madre, y la tacha de desgraciada. sin embargo, no se juzga a sí mismo con las mismas reglas de conducta: la violencia en la relación de sus padres se repite en su relación con Lola; el embarazo de la madre, «vaya usted a saber de quién»" , se repite en el embarazo de Lola por El Estirao; la incapacidad de la madre de proveer vida, por sus vacios pechos ${ }^{12}$ se repite en la incapacidad de Pascual de tener un hijo que sobreviva; el rechazo de

\section{4 Ídem, pág. 30 .}

5 «Mi padre se sentaba en el suelo, a la vera del cajón, y mirando para la hija se le pasaban las horas, con una cara de enamorado... a la hora a que menos costumbre teníamos de verlo venir allí lo teníamos, otra vez al lado del cajón, con la cara blanda y la mirada tan humilde...», Ídem, pág. 37.

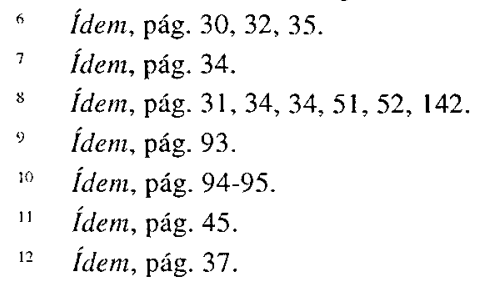


Mario ante la paliza del señor Rafael se repite en el comportamiento de Pascual, que tampoco lo acoge, temiendo parecer blando ${ }^{13}$ ante el otro. Pascual juzga y condena a su madre, pero no se siente obligado a sentenciarse a sí mismo por idénticos pecados ${ }^{14}$.

Todo el lenguaje que emplea Pascual para describir a su madre y a sus acciones tiene matiz negativo. Estos elementos negativos van sumándose, y fortaleciéndose mientras crece el odio que siente Pascual. No debe perderse de vista que la madre, y la muerte de ella, son el eje del relato ${ }^{15}$. Pascual organiza su historia no por orden cronológico, sino por orden de asesinato ${ }^{16}$, mata a la Chispa, después a la yegua, al Estirao, y, finalmente, a la madre. La fiereza de Pascual es mayor en cada asesinato: en la muerte de la Chispa, tiene una reacción momentánea de rabia, y mata a la perra. La yegua tiene una muerte un poco más calculada e intencionada: la pelea con Zacarías ha servido para prevenir el crimen, y el avance de Pascual hacia la yegua es descrito como un baile de muerte. La muerte de El Estirao tiene raices profundas, y es ya prevista en el capítulo 3 con el primer encuentro y desafío, cumpliéndose en el capítulo 16. El eje del relato, la muerte de la madre, es cuando el odio de Pascual llega a un punto abismal. La progresión de estas muertes, planeada cuidadosamente por Pascual, priva de sensibilidad al lector, que llega a ver el último crimen como una muerte necesaria y razonada ${ }^{17}$.

La autobiografía aporta a Pascual otra herramienta para defenderse ante sus acciones: la omisión ${ }^{18}$. Pascual selecciona los hechos que contará ${ }^{19}$, dirigiendo

13 Ídem, pág. 50.

14 Esta falta de auto-censura también es apuntada por Mary Ann Beck, «Nuevo encuentro con La familia de Pascual Duarte», cit., cuando dice Beck, «Mayor ironía que ésta no cabe, pues si bien Pascual es incapaz de tolerar el más leve mal en los demás, paradojicamente se apoya en él para justificar el hacer un mal de mucha mayor proporción. No censura en él mismo el odio hacia la madre y los deseos de matarla, sino que los justifica por el mal que en ella hay» (pág. 296).

is John R. Rosenberg, en su estudio «Pascual Duarte and the Eye of the Beholder: Cela, Sartre, and the Methafor of Vision» (Revista Canadiense de Estudios Hispánicos, Vol. XIV, ${ }^{\circ} 1$, otoño 1989), dice: «She [la madre] receives the cruhing weight of Pascual's hate and is the character most dominated by his narrative vision» (pág. 155).

16 Dru Doughtery, en su estudio «Pascual en la cárcel: El encubierto relato de La familia de Pascual Duarte» (ínsula, 1977, $\mathrm{n}^{\circ} 365,5-6$ ), apunta la falta de orden lineal, y señala que el lector necesariamente tiene que reconstruir una orden cronológica, así participando en la novela activamente (pág. 5).

17 Mary Ann Beck ( cir.) advierte que «si el lector no lee «con agudeza», se deja arrastrar por el persuasivo discurrir de Pascual sin examinar rigurosamente los hechos en sí», (pág. 284). Después aclara Beck que no hay que ceer las justificaciones del narrador, pues «si hay elección, no se es víctima» (pág. 285).

18 John Kronik examina el espacio físico y narrativo en su estudio «Pascual's Parole» (The Review of Contemporary Fiction, otoño 1984, pág. 111-119) y declara que: «as he [Pascual] writes he creates a new Character (in both senses of that term)...» (pág. 116).

19 Quizás la omisión más notable de Pascual es la falta de detalles sobre el asesinato de Don Jesús González de la Riva. Es el crimen que le asegura a Pascual la muerte, pero su porqué queda 
al lector por un solo camino de interpretación. Es interesante señalar que Pascual omite la mención de su madre en muchas ocasiones: en el entierro de Mario; en la boda con Lola; en el aborto de Lola. Pascual sólo presenta a su madre cuando está dispuesto a añadirle elementos de maldad.

Este tratamiento de la madre impide que el lector tenga la posibilidad de encontrar en ella cualidades que merezcan simpatía, suscitando a la vez el tema del nombre: tal como he dicho, la madre es el único personaje que no lo tiene. Un nombre identifica y distingue a un ser particular de otro. La falta de nombre acaba con la individualidad de un personaje; le quita la humanidad, relegándole a una tipología mal definida ${ }^{20}$. Esto es exactamente lo que Pascual quiere: que no haya ningún rasgo humano en su madre. Lo humano deja paso a la comprensión de las acciones de un personaje, y permite que se entienda mejor el carácter humano, el cual suele ser una mezcla de bueno y malo. La presentación del padre es de un ser humano particular: Estéban Duarte Diniz, portugués; tiene elementos violentos en su carácter, pero se salva por la ternura y amor que muestra hacia Rosario ${ }^{21}$. En cambio, Pascual no ofrece salvación a la madre, sino que la deja indefinida, no nombrada, ausente muchas veces, y siempre descrita por reproches.

Analizar el tratamiento de la madre suscita el problema de culpabilidad que siente Pascual: ¿quién tiene la culpa por las acciones de él? Muchos críticos han avanzado teorías diversas, entre ellas, echándole la culpa a la sociedad española de la época ${ }^{22}$, al destino ${ }^{23}$, a las clases sociales ${ }^{24}$, al machismo ${ }^{25}$, a la madre ${ }^{26} \mathrm{y}$ a la familia fallada ${ }^{27}$. Es cierto que Pascual busca asignar culpabilidad a través

encerrado en un silencio sorprendente. Por eso, muchos críticos han intentado verlo como la clave del libre, entre ellos Alonso Zamora Vicente, Gonzalo Sobejano, y Martín Martínez.

20 Mary Ann Beck ( cit.) comenta sobre este aspecto de la presentación de Pascual de hacer que el lector piense que las víctimas son seres peores que él, lo cual provee justificación a los actos de violencia. Beck no está de acuerdo con los críticos que concuerdan con Pascual, sino que cree que Pascual actúa con venganza, y no justicia (pág. 287).

21 Véase nota 5.

22 Véase: Gonzalo Sobejano, Novela española de nuestro tiempo, Madrid, 1975; Pablo GilCasado, La novela social española Barcelona: Seix Barral, 1973; Arnold M. Penuel, «The Psycology of Cultural Disintegration in Cela's La fanilia de Pascual Duarte», Revista de Estudios Hispánicos, 16: 3, octubre 1982, pág. 361-378.

23 Véase Cedric Busette, «La familia de Pascual Duarte and the Prominence of Fate» Revista de Estudios Hispánicos, 8, 1974, pág. 61-67.

24 Véase: Robert Spires, Op. cit.; Paul Ilie, ob. cit.; Robert Kirsner, The Novels and travels of Camilo José Cela Chapel Hill: Univ. of North Carolina Press, 1963.

25 Véase: Jo Evans, «La familia de Pascual Duarte and the Search for Gendered Identity» Bulletin of Hispanic studies, LXXI, 1994, pág. 197-216; Carlos Jérez-Farrán, «Pascual Duarte y la susceptibilidad viril» Hispanófila, 32:2, enero 1989, pág. 47-63.

26 Véase J. S. Bernstein «Pascual Duarte and Orestes» Symposium, XXII, invierno, 1968, pág. $301-308$.

27 Véase: A. Hoyle, «La familia de Pascual duarte: psicoanálisis de la historia» Actas del VIII Congreso Internacional de Hispanistas, 22-27 de Agosto 1983, ed. Kossoff, Vázquez, Kossoff y 
de todo su relato, formando así un subtema al texto. Pascual varía su censura, vacilando entre el instinto ${ }^{28}$, el destino, ejemplificado por los dos caminos que llevan hacia la muerte, uno de flores y otro de $\operatorname{cardos}^{29}$, y también, inculpando al otro con quien pelea o a quien mata ${ }^{30}$. En el capítulo 13 Pascual se declara confesado y perdonado por Dios, sugiriendo que finalmente aceptó la responsabilidad por los crímenes, y se arrepintió. Sin embargo, confiesa al lector que no ha entendido bien las palabras del sacerdote, y que tampoco pudo quitarse de la mente los pensamientos malignos ${ }^{31}$. Pascual dice haberse arrepentido, pero borra las líneas de la confesión con la segunda confesión dirigida al lector, dejando a éste incierto del verdadero remordimiento de Pascual ${ }^{32}$. Por cierto en el capítulo 15, cuando vuelve de su estancia en La Coruña, torna a invocar al instinto del hombre como culpable en sus acciones ${ }^{33}$, pues parece cierto que Pascual nunca se considera responsable de sus actos ${ }^{34}$. La progresión del odio

Ribbans, Tomo II, Ediciones Istmo, Madrid, 1986; Matías Montes-Huidobro, «Dinámica de la correlación existencial en La familia de Pascual Duarte» Revista de Estudios Hispánicos, 16: 2 , mayo 1982 pág. 213-222.

28 Véase William M. Sherzer, «Primitivism in La familia de Pascual Duarte» Discurso literario, 5:2, primavera 1988, pág. 473-482.

20) La familia de Pascual Duarte, cit., pág. 21.

3 Cuando mata a la chispa, es por su mirada: «La perra seguía mirándome fija, como si no me hubiera visto nunca, como si fuese a culparme de algo de un momento a otro, y su mirada me calentaba la sangre de las venas de tal manera que se veía llegar el momento en que tuviese que entregarme;...» idem (pág. 28).

Al describir la pelea con Zacarías, dice, «porque si Zacarías se hubiera estado callado como Dios manda y no se hubiese metido en camisas de once varas, entonces se hubiera ahorrado un disgustillo...» (pág. 78). Después, de camino a casa con sus amigos, comenta: «Él se lo buscó; la conciencia bien tranquila la tengo. ¡Si no hubiera hablado!» (pág. 80).

La muerte de El Estirao va precedida de unos reproches en la actitud de éste: «Estaba bravo el mozo» (pág. 130). «Era demasiado chulería» (pág. 131).

En al muerte de su madre, Pascual prevee la culpabilidad de su madre en el capítulo 12, al despertarse clla: «Como la alcoba es vieja, los muebles nos asustan con su crujir que puede despertarlo, que a lo mejor había de precipitar las puñaladas» (pág. 102). En efecto, así ocurre: «Di la vuelta para marchar. El suelo crujía. Mi madre se revolvió en la cama. -¿Quién anda ahí? Entonces sí que ya no había solución» (pág 156). El lector, ya prevenido desde hace 6 capítulos, debe echarle la culpa a la madre tambiên.

"ildem, pág. 107.

32 Robert Spires trata el tema de las incongruencias a través de la novela, las cuales obligan al lector a perder confianza ante las palabras del narrador. ( $($ Systematic Doubt...» cit.). Dru Dougherty ( cit.) también apunta que la confesión de Pascual es literaria, y no religiosa (pág. 5).

33 «Si mi condición de hombre me hubiera permitido perdonar, hubiera perdonado, pero el mundo es como es y el que quiere avanzar contra corriente no es sino vano intento». La fanilia de Pascual Duarte, cit., pág. 121.

\$4 John Rosenberg, en el estudio «El autobiógrafo encerrado: Pascual Duarte y su transcriptor» Explicación de textos literarios, 14: 2, 1985-86, pág. 63-72, apunta que la meta del narrador es producir una autojustificación por los actos violentos de su vida. Además, Rosenberg ve en la primera línea del narrador ( «Yo, señor, no soy malo, aunque no me faltarían motivos para serlo» cit. pág. 21) la naturaleza de apología del texto. 
que siente hacia su madre puede interpretarse como una acusación callada ${ }^{35}$. El relato entero busca asignar culpabilidad a cualquier otra fuerza que no sea Pascual Duarte. En este caso, hay gato emncerrado: la insistencia en fuerzas ajenas indica que Pascual rehúye una verdad no apetecible.

En la última escena, en la muerte de su madre, Pascual se descubre como el culpable de todo, e indica claramente que tiene consciencia de su responsabilidad en el crimen. es el único momento de honradez en el relato del condenado, que demuestra que todo ha sido un intento de engañar, de justificarse y pedir al lector que le dé la razón ${ }^{36}$.

«En una de las vueltas vi a mi mujer, blanca como una muerta, parada a la puerta sin atreverse a entrar. Traía un candil en la mano, el candil a cuya luz pude ver la cara de mi madre, morada como un hábito de nazareno...

La sangre corría como desbocada y me golpeó la cara. estaba caliente como un vientre y sabia lo mismo que la sangre de los corderos (pág.1567$157)^{37} . »$

¡La madre se compara al nazareno! Sacrificado para que pudieran salvarse otros, y asesinado por los paganos no creyentes. Pascual emplea la metáfora, quizás enfocándose en la salvación suya: «Podía respirar...» (pág. 157). Sin embargo, al emplear el símbolo de Jesús para describir a su madre, necesariamente se pone a sí mismo al otro lado, convirtiéndose en los soldados romanos responsables por la muerte del Salvador.

Si esto no fuera bastante sorprendente, la metáfora del nazareno va seguida de otra, también religiosa, en la cual la madre equivale a un cordero sacrifica$\mathrm{do}^{38}$. Por primera vez en la narración, el hijo emplea palabras positivas para describir a su madre, y es exactamente en el momento en que la mata. De esta

35 Adolfo Marín-Minguillón, en su estudio «La familia de Pascual Duarte y el efecto esquizo» Crytical Essays on the Literatures of Spain and Spanish américa, Boulder: Society of Spanish and Spanish American Studies, vii, 1991 dice: «el narrador irá estrechando progresivamente el cerco acusatorio sobre su madre, a quien la implica en todas sus desgracias...» (pág. 176).

${ }^{36}$ Rose Marie Marcone, en su estudio «Implications of the Autobiographical Form in $L a$ familia de Pascual Duarte» The USF Language Quaterly, XXIC/ 1-2, otoño-invierno, 1985, pág. 13-15, dice que la narración es un intento de auto-análisis, en el cual Pascual trata de entender su vida. Marcone dice que fracasa Pascual, pero que logra tener más consciencia en sus actos, lo cual le permite «experience the degree of despair necessary for the writting of the confessions» (pág. 14). Esta creciente consciencia, según Marcone, no puede extinguirse una vez descubierta, pero tampoco conocemos los lectores si Pascual da el último paso en aceptar la responsabilidad. «No answers are given nor are motives provided. He considers himself a victim of circumstance to the very end» (pág. 14).

37 Las cursivas mías.

38 Juan Antonio Masoliver Róden, en su estudio «Las dos lecturas de La familia de Pascual Duarte» Ínsula, 518/519, febrero-marzo 1990, pág. 51-52, trata el empleo del símbolo del cordero en relación con Pascual, y menciona cuando lo emplea para describir la madre. Cita a Cirlot, quien relaciona el cordero con «pureza, inocencia, mansedumbre e inmerecido sacrificio». Sin embargo, Masoliver relaciona a Pascual con la figura de Cristo, cuando claramente es la madre la que se relaciona con él. 
forma, Pascual solamente reconoce, durante unos breves imnstantes, que la responsabilidad de la muerte es completa y únicamente suya: la madre no tiene la culpa, ni mucho menos la tienen el destino o los instintos. Pascual Duarte ha matado a su madre en un acto reprensible, descarado y vergonzoso. La presentación totalmente negativa de la madre ha sido un engaño; la última revelación cs que la madre se ha salvado, su salvación equivale a la perdición y culpabilidad de Pascual.

Si a través de toda su narración Pascual Duarte rehúye la responsabilidad de sus actos violentos, es al final cuando se vacía su conciencia, empleando dos metáforas para describir a su madre que solamente se pueden interpretar como verdadera confesión de Pascual. El relato termina poco después, Pascual corriendo y respirando con alivio. ¿Experimentará alivio también al reconocer su responsabilidad? ¿O simplemente nos ha sido dada una pista para poder entrever los verdaderos sentimientos de Pascual?

Como bien señala Spires ${ }^{39}$, las incongruencias solamente añaden nuevas y ricas interpretaciones en la obra. Y este estudio ofrece otra: la madre de Pascual Duarte salvada, rescatada del basurero donde el hijo la tenía escondida.

\footnotetext{
30 Robert Spires, «Systematic Doubt...», cit.
} 